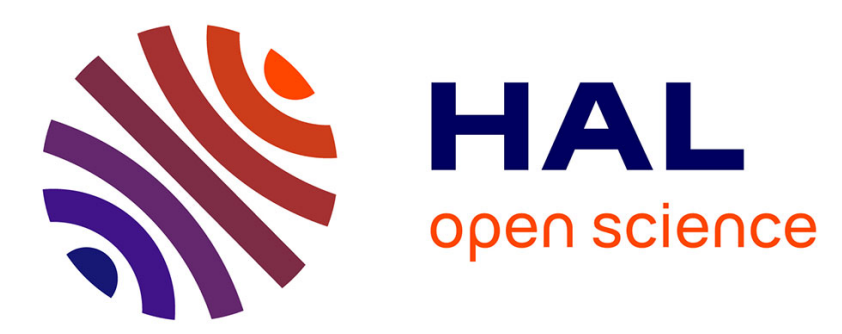

\title{
Longitudinal follow-up of fitness during childhood: interaction with physical activity
}

G. Baquet, Jos W.R. Twisk, Han C.G. Kemper, Emmanuel van Praagh, Serge Berthoin

\section{- To cite this version:}

G. Baquet, Jos W.R. Twisk, Han C.G. Kemper, Emmanuel van Praagh, Serge Berthoin. Longitudinal follow-up of fitness during childhood: interaction with physical activity. American Journal of Human Biology, 2005, American Journal of Human Biology, 18 (1), pp.51-58. 10.1002/ajhb.20466 . hal02394163

\section{HAL Id: hal-02394163 \\ https://hal.univ-lille.fr/hal-02394163}

Submitted on 4 Dec 2019

HAL is a multi-disciplinary open access archive for the deposit and dissemination of scientific research documents, whether they are published or not. The documents may come from teaching and research institutions in France or abroad, or from public or private research centers.
L'archive ouverte pluridisciplinaire HAL, est destinée au dépôt et à la diffusion de documents scientifiques de niveau recherche, publiés ou non, émanant des établissements d'enseignement et de recherche français ou étrangers, des laboratoires publics ou privés. 
Title: Longitudinal Follow-Up of Fitness during Childhood: Interaction with Physical Activity

Authors: G. Baquet ${ }^{1}$, J.W.R. Twisk ${ }^{2}$, H.C.G. Kemper ${ }^{3}$, E. Van Praagh ${ }^{4}$, and S. Berthoin ${ }^{1}$.

${ }^{1}$ : Laboratory of Human Movement Studies (EA 3608), Faculty of Sport Sciences and Physical Education, University of Lille 2, France.

2: Department of Clinical Epidemiology and Biostatistics, VU University Medical Centre (VUMc), Amsterdam, The Netherlands.

${ }^{3}$ : Institute for Research in Extramural Medicine, VU University Medical Centre (VUMc), Amsterdam, The Netherlands.

${ }^{4}$ : Laboratory of Biology of Physical Activity and Sport, Auvergne and Blaise Pascal Universities, Clermont-Ferrand, France.

21 pages including 31 references and 3 tables.

Running title: Fitness and physical activity in children.

Author to whom all correspondence should be addressed Berthoin Serge Laboratory of Human Movement Studies $\quad$ EA 3608 Faculty of Sport Sciences and Physical Education 9 rue de l'Université $\quad 59790$ Ronchin France Tel: $0033320887365 \quad$ Fax: 0033320887363

E-mail: serge.berthoin@univ-lille2.fr 


\section{ABSTRACT}

Purpose: To analyze health related fitness values during childhood (11- to 16-years) in relation to changes in physical activity level.

Methods: One hundred and fifty eight children were monitored over a 4-year period. Twice a year, they performed six physical fitness tests: standing broad jump, 10*5 meter shuttle run, sit-and-reach, hand grip, number of sit-ups in 30 seconds, 20 meter shuttle run. Height was measured four times a year to assess age at peak height velocity. Physical activity was assessed with a self-administered questionnaire at baseline and at the end of the follow-up. The physical activity level was defined by the frequency and the time spent in moderate to vigorous physical activities. Two groups were constituted: regularly active and sedentary.

Results: A multiple linear multilevel regression analysis was used to analyze the longitudinal relationships between changes in physical activity and physical fitness levels. Corrections were made for both time-dependent (time) and time-independent (sex) variables. Except for flexibility, boys' fitness performances increased more than the girl's ones. Positive and significant $(\mathrm{p}<0.05)$ regression coefficients were found with the regularly active for standing broad jump, 20-meter shuttle run, number of sit-ups, $10 * 5$ meter shuttle run in both sexes and for the girls' sit-and-reach performance. Increasing or decreasing physical activity level was not associated with changes in fitness performances over time, except for flexibility for the girls and the 20-meter shuttle run for the boys.

Conclusions: From childhood to adolescence, increasing physical activity is not sufficient to be fitter. The children who are stayed the most active were the fittest, particularly for the girls.

\section{KEY WORDS}

Children - Adolescent - EUROFIT - Multilevel Analysis 


\section{INTRODUCTION}

Physical activity and physical fitness are concepts that are often used in a confused manner and sometimes considered as synonymous. However, although they are thought to be correlated, they are not the same. Bouchard and Shephard (1994) have defined physical activity as any body movement produced by the skeletal muscles and resulting in a substantial increase over the resting energy expenditure. Epidemiological studies have shown that during growth, habitual physical activity and its intensity (Trost et al., 2002) decrease for boys as well as for girls. The concept of physical fitness has evolved from performancerelated to health-related fitness (AAPHERD, 1984), and includes cardiorespiratory endurance, muscular strength, flexibility and body composition. Both physical activity (Janz and Mahoney, 1994) and physical fitness (Rowland and Freedson, 1994) are related to health outcomes. The evolution indicators (inter-age correlations) of physical fitness and physical activity level from childhood to adolescence tend to be moderate (Malina, 2001). Nevertheless, some longitudinal studies have indicated that the more active children and adolescents will become the more active adults (Telama and Yang, 2000). Physical activity and physical fitness levels have different relationships with cardiovascular disease risks (Twisk et al., 2002; Williams, 2001). This suggests that even if physical activity increases the physical fitness level, inactivity is not the principal cause of being unfit. Thus, the purpose of the present study was twofold:

1) What are the changes over four years (i.e. between 11 and 15 years -old) in anthropometry, physical fitness and physical activity levels?

2) What are the relationships between physical fitness and changes in physical activity levels over a four-year period? 


\section{METHODS}

\section{Design}

The study was initiated in September 1997 and received the approval of the Lille Consultative Committee for the Protection of Persons in Biomedical research, to collect the data. Before testing was stared, children and their parents received a verbal description of the experiment and completed a written, informed consent form. One hundred and ninety-three children volunteered to enter the study. The 98 girls and 95 boys were followed over a fouryear period from September 1997 to June 2001. Fitness tests and anthropometric measurements were performed at the beginning and at the end of the school year (September and June of each year). Height was measured four times a year, four months apart, over the four years. Based on height measurements, height velocities were estimated 4-monthly. The relationship between height velocity and age was drawn for each subject. Peak height velocity (PHV) was mathematically estimated for each subject. Maturity status was determined with respect to age at PHV. In order to have a more homogeneous biological age group, only subjects whose age at PHV was observed (i.e. prepubertal at the start of the study) were included in the study. Fourteen girls and 2 boys, whom PHV was not identified, were not included in the study. A self-administered questionnaire to assess physical activity levels was presented to the children at the beginning and at the end of the study (Narring and Michaud, 1995; Narring et al., 1999).

\section{Anthropometry}

Height and body mass were measured with a wall stadiometer (Vivioz medical) and a calibrated beam balance (Tanita TBF 543). Percentage of body fat was estimated from skinfold thickness $(0.1 \mathrm{~mm})$ with a Harpenden caliper (Harpenden Inc.) measured at three sites (biceps, triceps and calf), according to Lohman (1992). Body mass index (BMI) was 
calculated from body mass $(\mathrm{kg})$ and height $(\mathrm{m})$ : BMI $\left(\mathrm{kg} \cdot \mathrm{m}^{-2}\right)$. The ratio between the waist circumference and the hip circumference was also measured.

\section{Fitness tests}

Subjects performed six field tests, which were part of the European Fitness Tests (EUROFIT) battery. To achieve EUROFIT standards, the recommendations of the Committee of Experts on Sports Research were observed (1988). The selected tests were standing broad jump (explosive strength, in $\mathrm{cm}$ ), 10*5 meter shuttle run (speed-coordination in s), hand grip (static strength, in N.kg-1; T.K.K. 5101, Takei Inc.), sit-and-reach (flexibility, in cm), the number of sit-ups in 30 seconds (functional strength, number) and 20 meter shuttle run (cardiorespiratory endurance, in $\mathrm{km} \cdot \mathrm{h}^{-1}$ ). In a literature review, Renson (1988) had noticed the highly reproducibility of these physical fitness tests.

\section{Physical activity}

Physical activity questionnaires developed for French language children (Narring and Michaud, 1995; Narring et al., 1999) were delivered to the children during class sessions. The children received a precise explanation of each item to avoid any ambiguity and completed the questionnaires themselves, the experimenters simply reminding them to check or circle the number of their answers and leaving them the necessary time to answer in the most precise manner possible. To assess physical activity, children and adolescents had to determine the type, the number and the time spent in formal or informal physical activities during the last week, with a detailed one-page diary listing the number and types of sports and physical activity episodes each of them had engaged in. From these questionnaires, the children were divided retrospectively into two groups, according to their physical activity level at baseline. This habitual physical activity level was defined by the frequency and the 
time spent in moderate to vigorous physical activities (MVPA). The groups were constituted: as regularly active and sedentary. The regularly active children spent more than one hour a day at MVPA. The children considered as being sedentary spent an hour or less at MVPA (Cavill et al., 2001).

\section{Statistical analysis}

At the end of the study, 84 girls and 74 boys had completed the two questionnaires, performed all the field tests and had an identified PHV. Results are presented as mean \pm standard deviations (SD). The changes over four years in body composition and fitness variables were analyzed with Multilevel analysis (random coefficient analysis) (Twisk, 2003). In this Multilevel analysis (performed with MLwin software), both a random intercept and a random slope with age were considered. This method was also used to investigate the relationship between changes in physical activity level (predictor variables) and fitness variables (dependent variables), correcting for age. In all cases, stratified analyses were performed a priori for boys and girls. Change in physical activity was modeled as a categorical variable, in which the changes were defined as increase, decrease, unchanged regularly active and unchanged sedentary. The latter was used as reference category. The model is given with the intercept $\beta_{0}$ (estimation of the intercept), $\beta_{1}$ the regression coefficient for time (estimation of the slope) and the three fixed regression coefficients for changes in physical activity (physical activity level increase, physical activity level decrease and stay in regularly active group). These fixed regression coefficients are time-independent predictor variables (variation between subjects). Additional correction of age at PHV was also investigated in the statistical analysis. In addition, changes in the percentage of individuals changing activity groups were tested with the Cochran's Q test. In all cases, threshold for significance was set at $\mathrm{p}<0.05$. 


\section{RESULTS}

35 children (21 boys and 14 girls) were rejected for an unidentified PHV or for an incomplete data set in physical activity. No significant effect of age at PHV was found in the statistical analysis in both sexes and for all physical fitness items. The results are presented without additional correction of age at PHV.

1) What is the change over four years in anthropometry, physical fitness and physical activity?

Changes over time in anthropometric parameters and field test performances are displayed in Table 1. During the 4-year follow-up study, BMI was significantly increased $\left(2 \mathrm{~kg} \cdot \mathrm{m}^{-2}\right.$ and $2.7 \mathrm{~kg} \cdot \mathrm{m}^{-2}, \mathrm{p}<0.05$, for boys and girls, respectively). The percentage of body fat significantly decreased for the boys $(-6.3 \%, \mathrm{p}<0.05)$ and remained stable for the girls, while waist to hip ratio decreased significantly in girls $(-5.3 \%, \mathrm{p}<0.05)$ and remained stable for the boys. For boys, standing broad jump, handgrip, number of sits-up and 20-meter shuttle run performances increased and $10 * 5$ meter shuttle run times decreased significantly over the four-year period. In girls, a significant increase in standing broad jump, handgrip and sit-andreach performances and a significant decrease in $10 * 5$ meter shuttle run times were found. No change in 20-meter shuttle run performance was observed.

Table 2 reports the changes in physical activity over time. The time spent in MVPA and the number of children in the different physical activity change groups, are presented for both sexes. The number of children who were sedentary or regularly active is given at the beginning and at the end of the follow-up period. Over the 4 years, the mean time spent in MVPA remained stable for both boys and girls (-14 min.day ${ }^{-1}$ and -10 min.day ${ }^{-1}$ for boys and girls, respectively). From childhood to adolescence, the number of sedentary girls increased (+8.3\%), while 10 girls (11.9\%) increased their physical activity level and 18 girls $(21.4 \%)$ 
decreased it. The number of sedentary and regularly active boys remained stable, while 12 boys $(16.2 \%)$ increased their physical activity level and 14 boys $(18.9 \%)$ decreased it. For boys, most subjects stayed in the "regularly active" group (45.9\%), while most girls stayed in the "sedentary" group (53.6\%). No significant changes in the percentage of changing activity groups were found for both sexes. In addition, the time spent in MVPA decreased significantly for the sedentary boys.

2) What is the relationship between physical fitness and changes in physical activity levels over a 4-year period?

Table 3 summarizes the results of the multilevel analysis concerning changes in physical activity and physical fitness performances for boys and girls. Boys who increased their physical activity level showed significantly better performances (compared to the children who remained sedentary over time) in the $10 * 5$ meter shuttle run test and the 20 -meter shuttle run test. No significant association was found for the girls. Boys who decreased their physical activity level showed a better performance in the $10 * 5$-meter shuttle run test and the number of sit-ups in 30s. Girls who decreased their physical activity level showed a significantly lower performance on the sit-and-reach test. Children who stayed in the regularly active group showed better performances in all fitness tests compared to the children who remained sedentary over time. Only for handgrip (for boys and girls) and for the sit-and-reach (for boys), was there no statistically significant difference between groups.

\section{DISCUSSION}

This study examined changes in physical activity levels in relation with physical fitness in 158 children over a four-year period. It was found that increased physical activity level was not closely associated with significantly better physical fitness performances (compared to the sedentary subjects). The absolute values of the performances in physical fitness tests were 
not different between the children who increased or decreased their physical activity levels. Even more importantly, if children increased their physical activity level, they never reached the fitness performances of some who decreased their physical activity level, i.e; the children who were physically active at baseline. Physical fitness performances were more associated with maintaining a high level of physical activity. The regularly active group not only had higher performances in cardiorespiratory endurance, explosive and functional strength, speed coordination, and for the girls, flexibility, but also further increased these performances, compared with the other groups. So, the main result of the present study was that it appears important to promote physical activity early in childhood and for children to have a high level of physical activity.

\section{Development of anthropometry, fitness and activity over time}

Physical characteristics were similar to the literature (Thompson et al., 2002. Sardinha et al., 2003). BMI data showed a significant increase in boys and in girls (respectively, 0.55 and $0.69 \mathrm{~kg} \cdot \mathrm{m}^{-2}$ per year). Thompson et al. (2002) have shown that, when BMI for both sexes was aligned on maturational age, there was no difference between boys and girls. They have reported a clear decrease from - 1 year to 1 year PHV (13.5 \pm 0.9 years) in sum of skinfolds for boys. In girls, the sum of skinfolds remained stable from -1 years to 2 years PHV. In the present study, the percentage of body fat was not significantly different in girls at the end of the follow-up, whereas the boys presented a significant trend for a lower percentage. For the girls, the average change over time for percentage of body was -0.14 , indicating an increase during the first year of the study and a decrease until the end of the follow-up. Regular physical activity is considered as an important factor in the regulation of body weight associated with a decrease in fatness. The girls were more sedentaries than the boys, but it is 
difficult to evaluate the effects of physical activity from maturity-associated changes in fatness.

Kemper et al. (1990) have shown that during adolescence, physical fitness performances increased in boys, and increased or remained stable in girls. During puberty, boys' performances are higher than that of the girls, except for flexibility. The results of the present study are similar; in addition they indicated that the performances improved significantly more in boys than in girls, except for muscular abdominal strength and flexibility. In boys, explosive strength, and handgrip were certainly influenced by a more pronounced muscular mass increase at puberty (Malina, 1994), while the increase in cardiovascular performance was linked with a decrease in energy cost of running (Krahenbuhl et al., 1989).

Several authors (Trost et al., 2002; Gavarry et al., 2003) have noticed the decline of physical activity from childhood to adolescence, using accelerometers or heart rate recorders. However, adolescent boys have always higher levels of moderate to vigorous physical activity than adolescent girls. In our study, time spent in MVPA declined from childhood to adolescence, but not from a significant manner (-14 min.day ${ }^{-1}$ and -10 min.day ${ }^{-1}$ for boys and girls, respectively), but stayed higher in boys than in girls (99 vs. 67 min.day ${ }^{-1}$ ). These results are in accordance with those of Telama and Yang (2000). They found that boys were more active than the girls at 12 and 15 years. However, there was a clear trend from sedentary in the present study. Boys who stayed in the sedentary group were significantly more sedentaries and the number of sedentary girls increased. Moreover, no significant difference were found between those who increased and those who decreased their physical activity level in both sexes. Although physical activity seems to be more stable over a short period, it is generally accepted that, during adolescence, the stability coefficients are weak to moderate (Malina, 1996). However, the problem is that physical activity can be measured in many different ways, such as by questionnaire, accelerometry, heart rate monitoring, etc. (Sirard 
and Pate, 2001). Besides this, physical activity can encompass not only habitual physical activity, but also sport activities, organized or not, inducing sweating or a peak heart rate. Self-report questionnaires are subjective methods relying on responses from children. The latter have difficulties to recall, quantify and categorize. The greatest limitation with this type of measure is the subjectivity inherent when individuals are asked to respond to questions about their behavior. Generally, the number of administrations needed to estimate physical activity is not clear for most of the questionnaires. (Sirard and Pate, 2001). A limitation of the present study was the assessment of the physical activity, only at baseline and at 4-years follow-up. Modelling physical activity as a categorical variable results in a significant loss of precision (in terms of time). Given the rather weak tracking tendencies of physical activity levels could have been significantly different during the middle years of the study when it was not evaluated. Clearly a child performing 20 minutes of activity at baseline could increase activity by 30 minutes per day and still be classified as sedentary. Although it was difficult to make up sub-groups with specific characteristics in the present study, the children were divided into sedentary or regularly active groups according to the United Kingdom Expert Consensus Conference (Cavill et al., 2001). Considered as regularly active were those that reached the primary guideline (i.e. they participated in physical activity of at least moderate intensity for one hour per day).

\section{Relationships between changes in physical activity and physical fitness levels}

A multilevel modeling approach was used to estimate the relationship between changes in physical activity and physical fitness performance over time. In the literature, for both children and adolescents, the relationships between physical activity and physical fitness are weak to moderate (Malina, 2001). Our results are in accordance with the literature insofar that the changes in physical activity level, from childhood to adolescence, had a marginal 
influence on physical fitness performances, compared to stable sedentary subjects. A high consistent physical activity level was related to a better performance in explosive strength (standing broad jump), cardiorespiratory endurance (20-meter shuttle run test), speedcoordination $(10 * 5 \mathrm{~m}$ shuttle run test), flexibility (sit-and-reach) and functional strength (number of sit-ups) in girls, and in explosive strength, speed-coordination, functional strength and cardiorespiratory endurance in boys. Cardiorespiratory endurance performances are dependent on the physical activity level. Kemper (1999) has reported that the higher performances of boys compared to girls, and the decrease in aerobic performances for both sexes over the years are thought to be due to the intensity of physical activity, independently of its duration (Kemper, 1999). Blair et al. (1989) had showed that there was no significant difference between performances on a 1 mile running test in non-active and active 10 to 12 year old children, while such a difference existed in 13 to 15 year olds and adolescents over 16. Aerobic power is generally considered as a good health indicator (Krahenbuhl et al., 1985). Although the methods used to classify physical activity level are diverse, the most active subjects have higher cardiorespiratory fitness, while functional strength, flexibility and body composition are not correlated to physical activity level (Malina, 2001). Beunen et al. (1992) found no significant influence of physical activity levels on physical fitness test performances for flexibility, functional strength and percentage of fat mass, in adolescents aged 13 to 18 years. Huang and Malina (2002) have also shown that the more active children had higher cardiorespiratory endurance and flexibility than the less active. In the present study, there was no significant relationship between handgrip and changes in physical activity. If the strength increase during puberty was significantly higher in boys than in girls, static strength was generally not correlated to the physical activity level (Katzmarzyk et al., 1998). In the present study, the negative correlation found for the $10 * 5$ meter shuttle run test with changes in the level of physical activity indicates that those who were regularly active 
seemed to be the fastest (however, not significantly for boys). The latter, even those whose physical activity level decreased, significantly increased their performances compared to the sedentary subjects. Thus, physical activity levels or changes in activity levels appear to have less influence on speed and coordination than maturity or growth.

In conclusion, the main findings of this study were that, from childhood to adolescence, increasing physical activity is a not sufficient to be fit. The children who were the most active were also the fittest over the four-year period. 


\section{REFERENCES}

AAPHERD. 1984. Technical manual, health related physical fitness. Reston, VA, American Association for Health, Physical Education, Recreation and Dance.

Beunen G, Malina RM, Renson R, Simons J, Ostyn M, Lefevre J. 1992. Physical activity and growth, maturation and performance : A longitudinal study. Med Sci Sports Exerc 24:576585.

Blair SN, Clark DG, Cureton KJ, Powell KE. 1989. Exercise and fitness in childhood: implications for a lifetime of health. In: Gisolfi CV, Lamb DR, editors. Perspective in exercise science and sports medicine: youth, exercise and sport. Indianapolis, IN: Benchmark Press. p 401-430.

Bouchard C, Shephard RJ. 1994. Physical activity, fitness and health: The model and the key concepts. In: Bouchard C, Shephard RJ, Stephens T, editors. Physical activity, fitness and health. Champaign, IL: Human Kinetics. p 77-88.

Cavill N, Biddle S, Sallis JF. 2001. Health enhancing physical activity for young people: state of the United Kingdom Expert Consensus Conference. Pediatr Exerc Sci 14:12-25.

Commitee of Experts on Sports Research. 1988. Handbook for the Eurofit tests of physical fitness. Rome, Edigraf Editoriale Grafica.

Gavarry O, Giacomoni M, Bernard T, Seymat M, and G Falgairette. 2003. Habitual physical activity in children and adolescent during school and free days. Med Sci Sports Exerc 35: $525-531$.

Huang YC, Malina RM. 2002. Physical activity and health-related physical fitness in Taiwanese adolescents. J Physiol Anthropol Appl Human Sci 21:11-19.

Janz KF, Mahoney LT. 1994. Three-year follow-up of changes in aerobic fitness during puberty: The Muscatine study. Res Q Exerc Sport 68:1-9. 
Katzmarzyk PT, Malina RM, Song TM, Bouchard C. 1998. Physical activity and healthrelated fitness in youth: a multivariate analysis. Med Sci Sports Exerc 30:709-714.

Kemper HCG, Verschuur R, De Mey L, Storm van Essen L, Van Zundert A. 1990. Longitudinal changes in physical fitness of males and females from age 12 to 23: The Amsterdam growth and health study. Hermes 21:299-314.

Kemper HCG. 1999. Longitudinal studies of health and fitness of teenagers and the interaction with sports activity. Medicina Sportiva 3:85-102.

Kemper, HCG and LLJ Koppes. 2004. Is physical activity important for aerobic power in young males and females? In: Amsterdam Growth and Health Longitudinal Study; a 23-year follow-up from teenager to adult about lifestyle and health. J. Borms, M. Hebbelinck and A.P. Hills, editors. Medicine and Sport Science, vol 47, Basel. p 153-156.

Krahenbuhl GS, Skinner JS, Kohrt WM. 1985. Developmental aspects of maximal aerobic power in children. Physical growth and biological maturation of young athletes. Exerc Sport Sci Rev 13:503-538.

Krahenbuhl GS, Morgan DW, Pangrazi RP. 1989. Longitudinal changes in distance-running performance of young males. Int J Sports Med 10: 92-96.

Lohman TG. 1992. Advances in body composition assessment. Champaign, IL, Human Kinetics. p 65-77.

Malina RM. 1994. Physical activity: Relationship to growth, maturation, and physical fitness. In: Bouchard C, Shephard RJ, Stephens T, editors. Physical activity, fitness and health. Champaign, IL: Human Kinetics. p 918-930.

Malina RM. 1996. Tracking of physical activity and physical fitness across the lifespan. Res Q Exerc Sport 67, Suppl 3:48-57. 
Malina RM. 2001. Physical activity and fitness: pathways from childhood to adulthood. Am J Hum Biol 13:162-172.

Narring F, Michaud PA. 1995. Methodological issues in adolescent health surveys: The case of the Swiss multicenter adolescent survey on health. Soz Präventivmed 40:172-182.

Narring F, Cauderay M, Cavadini C, Michaud PA. 1999. Physical fitness and sport activity of children and adolescents: methodological aspects of a regional survey. Soz Praventivmed 44: $44-54$.

Renson R. 1988. Ontstaan, verantwoording en selectie van de EUROFIT-Motorische testbatterij Hermes 19:5-39.

Rowland TW, Freedson PS. 1994. Physical activity, fitness, and health in children: a close look. Pediatrics 93:669-672.

Sardinha LB, Going SB, Teixera PJ and T Lohman. 2003. Receiver operating characteristic analysis of body mass index, triceps skinfold thickness, and arm girth for obesity screening in children and adolescents. Am J Clin Nutr 70: 1090-1095.

Sirard JR, Pate RR. 2001. Physical activity assessment in children and adolescents. Sports Med 31:439-454.

Telama R, Yang X, Laasko L, Viikari J. 1997. Physical activity in childhood and adolescence as predictor of physical activity in young adulthood. Am J Prev Med 14:317-323.

Telama R and Yang X. 2000. Decline of physical activity from youth to young adulthood in Finland. Med Sci Sports Exerc 32:1617-1622.

Thompson AM, Baxter-Jones ADG, Mirwald RL and DA Bailey. 2002. Secular trend in the development of fatness during childhood and adolescence. Am J Human Biol 14: 669-679. 
Trost SG, Pate RP, Sallis JF, Freedson PS, Taylor WC, Dowda M, Sirard J. 2002. Age and gender differences in objectively measured physical activity in youth. Med Sci Sport Exerc $34: 350-355$.

Twisk JWR, Kemper HCG, Van Mechelen W. 2002. Prediction of cardiovascular disease risk factors later in life by physical activity and physical fitness in youth: Generals comments and conclusions. Int J Sports Med Suppl 1; 23:S1-S50.

Twisk JWR. 2003. Applied longitudinal data analysis for epidemiology. A practical guide. University Press, Cambridge.

Williams PT. 2001. Physical fitness and activity as separate heart disease risk factors: a metaanalysis. Med Sci Sports Exerc 33:754-761. 

TABLE 1. Changes in anthropometry and field test performances over a 4-year period (September 1997- June 2001)

\begin{tabular}{|c|c|c|c|c|c|c|}
\hline & \multicolumn{3}{|c|}{ Boys $(n=74)$} & \multicolumn{3}{|c|}{ Girls $(n=84)$} \\
\hline & Sept 1997 & June 2001 & & Sept 1997 & June 2001 & \\
\hline & \multicolumn{2}{|c|}{ Mean $\pm \mathrm{SD}$} & $\begin{array}{l}\text { Average change over time } \\
\text { and confidence intervals }\end{array}$ & \multicolumn{2}{|c|}{ Mean \pm SD } & $\begin{array}{l}\text { Average change over time } \\
\text { and confidence intervals }\end{array}$ \\
\hline Age (years) & $11.5 \pm 0.6$ & $15.3 \pm 0.6$ & & $11.4 \pm 0.5$ & $15.2 \pm 0.5$ & \\
\hline Body mass (kg) & $40.1 \pm 8.3$ & $59.7 \pm 11.1$ & $5.49(5.01 / 5.97)^{*}$ & $41.7 \pm 9.9$ & $57.6 \pm 10.2$ & $4.29(3.81 / 4.77)^{*}$ \\
\hline Height $(\mathrm{cm})$ & $147.1 \pm 6.6$ & $170.1 \pm 8.1$ & $6.6(6.2 / 7)^{*}$ & $148.7 \pm 8.2$ & $163.6 \pm 6.6$ & $4.25(3.87 / 4.63)^{*}$ \\
\hline BMI $\left(\mathrm{kg} \cdot \mathrm{m}^{-2}\right)$ & $18.4 \pm 3.0$ & $20.4 \pm 2.9$ & $0.55(0.41 / 0.69)^{*}$ & $18.7 \pm 3.2$ & $21.4 \pm 3.4$ & $0.69(0.4 / 0.98)^{*}$ \\
\hline$\%$ body fat & $23.0 \pm 7.2$ & $16.7 \pm 7.9$ & $-1.66(-1.89 /-1.43)^{*}$ & $27.7 \pm 6$ & $28.3 \pm 8.3$ & $-0.14(-0.37 / 0.09)$ \\
\hline Waist/Hip ratio & $0.79 \pm 0.05$ & $0.79 \pm 0.05$ & $-0.003(-0.007 / 0.001)$ & $0.76 \pm 0.05$ & $0.72 \pm 0.05$ & $-0.011(-0.013 /-0.009)^{*}$ \\
\hline Standing broad jump $(\mathrm{cm})$ & $155.7 \pm 19.7$ & $192.2 \pm 28.3$ & $9.69(8.29 / 11.09)^{*}$ & $136.1 \pm 18.1$ & $145.1 \pm 22.9$ & $1.76(0.86 / 2.66)^{*}$ \\
\hline $10 * 5 \mathrm{~m}$ shuttle run test $(\mathrm{s})$ & $20.5 \pm 1.3$ & $18.4 \pm 1.3$ & $-0.58(-0.66 /-0.5)^{*}$ & $21.8 \pm 1.4$ & $20.5 \pm 1.4$ & $-0.42(-0.5 /-0.34)^{*}$ \\
\hline Sit and reach $(\mathrm{cm})$ & $17.2 \pm 6.5$ & $16.4 \pm 7.9$ & $-0.06(-0.41 / 0.29)$ & $19.6 \pm 6.6$ & $22.6 \pm 9.0$ & $0.53(0.11 / 0.95)^{*}$ \\
\hline Hand grip $\left(\mathrm{N} . k g^{-1}\right)$ & $4.31 \pm 0.88$ & $5.88 \pm 0.98$ & $0.49(0.45 / 0.53)^{*}$ & $3.82 \pm 0.78$ & $4.31 \pm 0.88$ & $0.2(0.1 / 0.3)^{*}$ \\
\hline Number of sit-ups in 30 s (n) & $16.2 \pm 4.0$ & $22.1 \pm 5.2$ & $1.36(1.03 / 1.69)^{*}$ & $12.5 \pm 4.4$ & $16.9 \pm 4.2$ & $1.05(0.83 / 1.27)^{*}$ \\
\hline $20 \mathrm{~m}$ shuttle run test $\left(\mathrm{km} \cdot \mathrm{h}^{-1}\right)$ & $10.4 \pm 0.8$ & $11.5 \pm 1.2$ & $0.23(0.17 / 0.29)^{*}$ & $9.7 \pm 0.6$ & $9.9 \pm 0.7$ & $-0.01(-0.05 / 0.03)$ \\
\hline
\end{tabular}

BMI: Body Mass Index, \% body fat: estimated percentage of body fat. *: A significant change over time with $\mathrm{p}<0.05$.

${ }^{\dagger}$ : Average change over time per year was estimated with multilevel analysis using all repeated measurements. 
TABLE 2. Changes in physical activity indicators over a 4-year period (September 1997- June 2001)

\begin{tabular}{|c|c|c|c|c|}
\hline & \multicolumn{2}{|c|}{ Boys $(n=74)$} & \multicolumn{2}{|c|}{ Girls $(n=84)$} \\
\hline & Sept 1997 & June 2001 & Sept 1997 & June 2001 \\
\hline & Mean \pm SD & Mean \pm SD & Mean \pm SD & Mean \pm SD \\
\hline Regularly active children/Sedentary children (n) & $48 / 26$ & $46 / 28$ & $29 / 55$ & $21 / 63$ \\
\hline MVPA (min.day ${ }^{-1}$ ) & $113 \pm 52$ & $99 \pm 53$ & $77 \pm 46$ & $67 \pm 56$ \\
\hline Increased their physical activity level & \multicolumn{2}{|c|}{12} & \multicolumn{2}{|c|}{10} \\
\hline MVPA (min.day ${ }^{-1}$ ) & $55 \pm 11$ & $138 \pm 5^{* * *}$ & $48 \pm 20$ & $158 \pm 30 * * *$ \\
\hline Decreased their physical activity level & \multicolumn{2}{|c|}{14} & \multicolumn{2}{|c|}{18} \\
\hline MVPA (min.day ${ }^{-1}$ ) & $147 \pm 31$ & $33 \pm 19 * * *$ & $130 \pm 31$ & $40 \pm 18 * * *$ \\
\hline Stayed in the Regularly Active group & \multicolumn{2}{|c|}{34} & \multicolumn{2}{|c|}{11} \\
\hline MVPA (min.day ${ }^{-1}$ ) & $146 \pm 30$ & $141 \pm 32$ & $136 \pm 28$ & $142 \pm 30$ \\
\hline Stayed in the Sedentary group & \multicolumn{2}{|c|}{14} & \multicolumn{2}{|c|}{45} \\
\hline MVPA (min.day ${ }^{-1}$ ) & $45 \pm 16$ & $25 \pm 13^{* *}$ & $43 \pm 19$ & $41 \pm 20$ \\
\hline
\end{tabular}

$* * *$ : A significant change over time with $\mathrm{p}<0.001 ; * *$ with $\mathrm{p}<0.01$. 
TABLE 3. The average difference and confidence intervals in field test performances for groups with different physical activity changes, estimated with a Multilevel analysis.

\begin{tabular}{cccc}
\hline Fitness tests & $\begin{array}{c}\text { Physical activity level increased } \\
(12 \text { boys and } 10 \text { girls })\end{array}$ & $\begin{array}{c}\text { Physical activity level decreased } \\
(14 \text { boys and } 10 \text { girls })\end{array}$ & $\begin{array}{c}\text { Stayed in Regularly Active group } \\
(34 \text { boys and } 11 \text { girls })\end{array}$ \\
\hline Standing broad jump $(\mathrm{cm})$ & $12.54(-2.62 / 27.70)$ boys & $7.90(-6.62 / 22.42)$ boys & $14.25(2.00 / 26.50)$ boys* \\
& $4.73(-0.34 / 14.67)$ girls & $7.49(-1.03 .14 / 16.01)$ girls & $15.28(6.69 / 23.87)$ girls* \\
$10 * 5$ m shuttle run test $(\mathrm{s})$ & $-0.79(-1.52 /-0.06)$ boys* & $-0.83(-1.53 /-0.13)$ boys* & $-0.84(-1.43 /-0.25)$ boys* \\
& $-0.06(-0.63 / 0.51)$ girls & $0.005(-0.044 / 0.49)$ girls & $-0.67(-1.23 /-0.11)$ girls* \\
Sit and reach $(\mathrm{cm})$ & $2.05(-2.65 / 6.75)$ boys & $0.72(-3.79 / 5.23)$ boys & $0.99(-2.81 / 4.79)$ boys \\
& $0.01(-1.57 / 1.59)$ girls & $-2.04(-3.39 /-0.69)$ girls* & $5.49(3.88 / 7.1)$ girls* \\
Hand grip $\left(\mathrm{N} . \mathrm{kg}^{-1}\right)$ & $-0.01(-0.64 / 0.062)$ boys & $0.011(-0.050 / 0.072)$ boys & $0.27(-0.24-0.75)$ boys \\
& $-0.3(-0.7 / 0.1)$ girls & $0.01(-0.40 / 0.42)$ girls & $0.3(-0.1 / 0.7)$ girls \\
Number of sit-ups in 30s $(\mathrm{n})$ & $-0.29(2.46 / 6.61)$ boys* & $3.74(1.10 / 6.38)$ boys* & $3.71(1.49 / 5.93)$ boys* \\
& $1.68(-0.3 / 3.66)$ girls & $-0.17(-1.88 / 1.54)$ girls & $2.56(0.7 / 4.42)$ girls* \\
20m shuttle run test $\left(\mathrm{km} . \mathrm{h}^{-1}\right)$ & $0.84(0.24 / 1.44)$ boys* & $0.37(-0.21 / 0.95)$ boys & $0.53(0.04 / 1.02)$ boys* \\
& $0.14(-0.21 / 0.49)$ girls & $0.02(-0.28 / 0.32)$ girls & $0.34-0.04 / 0.72)$ girls* \\
\hline
\end{tabular}

*: A significant change over time with $\mathrm{p}<0.05$. 